\title{
Evaluasi Ketersediaan Unsur Hara Fosfor (P) pada Lahan Sawah Intensif Kecamatan Sukamakmur Kabupaten Aceh Besar
}

(Evaluation of the Availability of Phosphorus Nutrients $(P)$ on Intensive Rice Fields in Sukamakmur District, Aceh Besar Regency)

\author{
Zainuddin $^{\mathbf{1}}$, Zuraida ${ }^{\mathbf{1}}$, Yadi Jufri ${ }^{\mathbf{*}}$ \\ ${ }^{1}$ Program Studi Ilmu Tanah, Fakultas Pertanian, Universitas Syiah Kuala \\ *Corresponding author: yadijufri@ unsyiah.ac.id
}

\begin{abstract}
Abstrak. Pemupukan fosfor (P) di lahan sawah seringkali dilakukan secara intensif pada setiap musim tanam, namun seringkali tanpa memperhatikan status hara $\mathrm{P}$ tanah, sehingga menyebabkan terjadinya penimbunan $\mathrm{P}$ di dalam tanah. Tujuan penelitian untuk mengetahui ketersediaan unsur hara fosfor dan mengetahui sistem pengelolaan lahan sawah yang menunjukkan hasil produksi yang berbeda. Metode yang digunakan yaitu metode deskriptif. Hasil penelitian kadar P-tersedia di Kecamatan Sukamakmur rata-rata pada lahan sawah berproduksi tinggi $21,83 \mathrm{ppm}$ dan pada lahan sawah berproduksi rendah $24,43 \mathrm{ppm}$, keduanya termasuk ke dalam kriteria sangat tinggi. Ketersediaan unsur P-total yaitu dengan rata-rata pada lahan sawah berproduksi tinggi $0,56 \mathrm{mg} / 100 \mathrm{~g}$ dan pada lahan sawah berproduksi rendah $0,89 \mathrm{mg} / 100 \mathrm{~g}$, keduanya termasuk ke dalam kriteria sangat rendah. Produksi padi pada lahan berproduksi rendah diakibatkan (1) akibat penggunaan pupuk yang tidak tepat waktu, (2) serangan penyakit dan hama seperti: hama wereng, walang sangit, ulat, keong dan tikus dan (3) irigasi tidak mencukupi sebagian petakan sawah.
\end{abstract}

Kata Kunci : Fosfor, Sawah, Produksi

Abstract. Phosphorus (P) fertilization in rice fields is often carried out intensively at each planting season, but often without regard to soil $\mathrm{P}$ nutrient status, causing the accumulation of $\mathrm{P}$ in the soil. The research objective is to determine the availability of phosphorus nutrients and to know the management system of rice fields which shows different production results. The method used is descriptive method. The results of the study of the levels of available $\mathrm{P}$ in Sukamakmur District on average in high-producing rice fields were $21.83 \mathrm{ppm}$ and in low-producing paddy fields $24.43 \mathrm{ppm}$, both of them included in the very high criteria. The availability of Ptotal elements is, on average, in high-yielding rice fields $0.56 \mathrm{mg} / 100 \mathrm{~g}$ and on low-producing rice fields 0.89 $\mathrm{mg} / 100 \mathrm{~g}$, both of which fall into the very low criteria. Rice production on low production land is caused by (1) due to the use of fertilizer that is not timely, (2) disease and pest attacks such as plant hopper, pest control, caterpillars, snails and rats and (3) insufficient irrigation in part of rice fields.

Keywords: Phosphorus, Rice Field, Production

\section{PENDAHULUAN}

Fosfor merupakan unsur hara esensial yang penting bagi tanaman dan keberadaannya tidak dapat digantikan unsur hara lainnya. Unsur hara fosfor $(\mathrm{P})$ pada tanaman padi dapat mendorong dalam pembentukan bulir gabah, sehingga dapat mendukung produksi yang maksimal dan memiliki kandungan gizi yang lebih baik sehubungan dengan kadar $\mathrm{P}$ dalam biji, sehingga kebutuhan fosfor bagi tanaman dalam jumlah yang relatif banyak.

Pemupukan fosfor di lahan sawah seringkali dilakukan secara intensif pada setiap musim tanam, Pemupukan fosfor secara intensif tanpa memperhatikan status unsur hara fosfor $(\mathrm{P})$ tanah dapat menyebabkan penimbunan unsur hara fosfor $(\mathrm{P})$ dalam tanah yang sebenarnya dapat digunakan sebagai sumber nutrisi $\mathrm{P}$ untuk tanaman padi. Penimbuna unsur $\mathrm{P}$ dalam lahan sawah terjadi karena sifat unsur $\mathrm{P}$ yang inmobil, sehingga kurang tersedia bagi tanaman. Tidak tersedianya unsur ini juga karena unsur hara fosfor $(\mathrm{P})$ dapat diikat oleh unsur 
$\mathrm{Al}$ dan $\mathrm{Fe}$ pada $\mathrm{pH}$ tanah rendah dan dapat diikat oleh unsur $\mathrm{Ca}$ pada $\mathrm{pH}$ tanah tinggi, dan juga penjerapan oleh koloid liat.

Kecamatan Sukamakmur merupakan salah satu kecamatan di Kabupaten Aceh Besar Provinsi Aceh, dengan luas wilayah $10.600 \mathrm{Ha}$ atau sekitar 1,50 \% dari luas wilayah Kabupaten Aceh Besar. Bedasarkan data Badan Penyuluhan Pertanian (BPP) luas sawah di daerah tersebut 1647 Ha dengan rata-rata produksi padi tertinggi dalam 4 tahun terakhir ini di Desa Luthu Lamweu yaitu 8,31 ton/ha dan produksi terendah di Desa Seumereng yaitu 5,59 ton/ha. Perbedaan jumlah produksi padi di daerah tersebut diduga kurangnya pengetahun petani tentang rekomendasi pemupukan terutama unsur hara fosfor yang tidak tepat guna khususnya pada budidaya padi sawah sehingga menjadi penyebab sebagian sawah mengalami rendahnya produksi yang dihasilkan.

\section{METODE PENELITIAN}

\section{Tempat dan Waktu Penelitian}

Penelitian dilakukan di lahan sawah intensif di Kecamatan Sukamakmur Kabupaten Aceh Besar dan analisis sampel tanah di Laboratorium Kimia Tanah Fakultas Pertanian Universitas Syiah Kuala.

\section{Metode yang digunakan}

Penelitian ini menggunakan metode deskriptif yaitu dengan melakukan survei dan pengambilan sampel tanah berdasarkan posisi lahan yaitu pada lahan sawah berproduksi tinggi dan pada lahan sawah berproduksi rendah berdasarkan data Badan Penyuluhan Pertanian (BPP) Kecamatan Sukamakmur Kabupaten Aceh Besar kemudian analisis di Laboratorium dan data disajikan dalam bentuk tabel.

\section{Pelaksanana Penelitian}

Penelitian ini terdiri beberapa tahapan yaitu persiapan awal berupa pengumpulan data primer berupa wawancara dilakukan pada petani atau kelompok tani di daerah tersebut, data skunder berupa data produksi padi dan rekomendasi pemupukan yang bersumber dari BPP Kecamatan Sukamakmur Kabupaten Aceh Besar dan penentuan lokasi pengambilan sampel tanah.

Sampel tanah diambil pada kedalaman 0-20 cm dari permukaan tanah pada dua lokasi yang berbeda yaitu pada lahan sawah produksi tinggi dan pada lahan sawah produksi rendah. Menentukan tempat pengambilan sampel tanah sebanyak 2 lokasi dengan masing-masing 3 kali ulangan, setiap ulangan terdapat 5 titik kemudian dikomposit menjadi satu sampel tanah, sehingga terdapat 6 sampel tanah, penentuan titik dilakukan dengan purpisive sampling, dimaksudkan agar sampel tanah yang diambil benar-benar representatif, kemudian sampel tanah dianalisis di Laboratorium. 


\section{Analisis Tanah}

Tabel 1. Aspek Sifat Kimia Tanah yang diamati di Laboratorium

\begin{tabular}{|c|c|c|}
\hline No & Aspek & Metode \\
\hline 1. & $\mathrm{pH} \mathrm{H}{ }_{2} \mathrm{O}$ & Elektrometrik/pH meter \\
\hline 2. & P tersedia (ppm) & Bray I \\
\hline 3. & $\mathrm{P}$ total $(\mathrm{mg} / 100 \mathrm{~g})$ & HCL $25 \%$ \\
\hline 4. & KTK (me/100 g) & $1 N^{N H_{4}}$ OAc pH 7 \\
\hline 5. & C-Organik (\%) & Walkley \& Black \\
\hline 6. & $\mathrm{Fe}(\mathrm{ppm})$ & $1 \mathrm{NNH}_{4} \mathrm{OAc} \mathrm{pH} 4,8$ \\
\hline 7. & $\mathrm{Ca}(\mathrm{me} / 100 \mathrm{~g})$ & $1 \mathrm{NNH}_{4} \mathrm{OAc} \mathrm{pH} 7$ \\
\hline
\end{tabular}

\section{HASIL DAN PEMBAHASAN}

\section{Ketersediaan Fosfor pada Lahan Sawah}

Pengambilan titik sampel lahan sawah berproduksi tinggi dan lahan sawah berproduksi rendah bertempat di Desa Luthu Lamweu dan Seumereng dengan masing-masing 3 kali ulangan. Hasil analisis tanah sawah berupa pH, P-tersedia (ppm), P-total (mg/100 g), KTK (me/100 g), C-organik (\%), Fe (ppm) dan Ca (me/100 g) diperoleh hasil sebagai berikut.

Tabel 2. Hasil Analisis Sifat Kimia Tanah Sawah Desa Leuthu Lamweu dan Seumereng

\begin{tabular}{|c|c|c|c|c|c|c|c|}
\hline \multicolumn{8}{|c|}{ Lahan Sawah Produksi Tinggi } \\
\hline $\begin{array}{c}\text { Kode } \\
\text { Sampel }\end{array}$ & $\begin{array}{c}\mathrm{pH} \\
\mathrm{H}_{2} \mathrm{O}\end{array}$ & $\begin{array}{l}\text { P-Tersedia } \\
\quad(\mathrm{ppm})\end{array}$ & $\begin{array}{c}\text { P-Total } \\
(\mathrm{mg} / 100 \mathrm{~g})\end{array}$ & $\begin{array}{c}\text { KTK } \\
(\mathrm{me} / 100 \mathrm{~g})\end{array}$ & $\begin{array}{c}\text { C-Organik } \\
(\%)\end{array}$ & $\begin{array}{c}\mathrm{Ca} \\
(\mathrm{me} / 100 \mathrm{~g})\end{array}$ & $\begin{array}{c}\mathrm{Fe} \\
(\mathrm{ppm})\end{array}$ \\
\hline L1 & $7,30^{\mathrm{n}}$ & $21,45^{\mathrm{st}}$ & $0,49^{\mathrm{sr}}$ & $63,18^{\mathrm{st}}$ & $2,42^{\mathrm{s}}$ & $34,29^{\mathrm{st}}$ & $2,28^{\mathrm{r}}$ \\
\hline L2 & $7,42^{\mathrm{n}}$ & $23,50^{\mathrm{st}}$ & $0,51^{\mathrm{sr}}$ & $78,40^{\text {st }}$ & $3,07^{\mathrm{t}}$ & $32,43^{\mathrm{st}}$ & $7,71^{\mathrm{r}}$ \\
\hline L3 & $7,33^{\mathrm{n}}$ & $20,55^{\text {st }}$ & $0,69^{\mathrm{sr}}$ & $64,37^{\text {st }}$ & $2,84^{\mathrm{s}}$ & $28,01^{\mathrm{st}}$ & 44,92 \\
\hline $\begin{array}{c}\text { Rata- } \\
\text { rata }\end{array}$ & $7,35^{\mathrm{n}}$ & $21,83 \mathrm{st}$ & $0,56^{\mathrm{sr}}$ & $68,64^{\text {st }}$ & $2,77^{\mathrm{s}}$ & $31,57^{\mathrm{st}}$ & $18,30^{s}$ \\
\hline \multicolumn{8}{|c|}{ Lahan Sawah Produksi Rendah } \\
\hline $\mathrm{S} 1$ & $7,26^{\mathrm{n}}$ & $23,10^{\mathrm{st}}$ & $0,21^{\mathrm{sr}}$ & $61,82^{\text {st }}$ & $2,79^{\mathrm{s}}$ & $36,43^{\text {st }}$ & $10,91^{s}$ \\
\hline $\mathrm{S} 2$ & $6,88^{\mathrm{n}}$ & $25,80^{\text {st }}$ & $1,12^{\mathrm{sr}}$ & $70,45^{\text {st }}$ & $2,53^{\mathrm{s}}$ & $41,74^{\text {st }}$ & $46,72^{\mathrm{s}}$ \\
\hline S3 & $7,58^{\mathrm{n}}$ & $24,41^{\text {st }}$ & $1,32^{\mathrm{sr}}$ & $64,96^{\mathrm{st}}$ & $3,48^{t}$ & $31,29^{\text {st }}$ & 37,67 \\
\hline Rata-rata & $7,24^{\mathrm{n}}$ & $24,43^{\mathrm{st}}$ & $0,89^{\mathrm{sr}}$ & $65,75^{\mathrm{st}}$ & $2,93^{\mathrm{s}}$ & $36,48^{\mathrm{st}}$ & $31,76^{\mathrm{s}}$ \\
\hline
\end{tabular}

Keterangan: Kriteria Penilaian Data Analisis Tanah; $\mathrm{n}=$ netral; $\mathrm{sr}=$ sangat rendah; $\mathrm{r}=$ rendah; $\mathrm{s}=$ sedang; $\mathrm{t}=$ tinggi; st = sangat tinggi.

\section{P-tersedia}

Hasil pengukuran P-tersedia pada lahan sawah berproduksi tinggi rata-rata 21,83 ppm sedangkan pada lahan sawah berproduksi rendah rata-rata $24,43 \mathrm{ppm}$, keduanya termasuk kriteria sangat tinggi (Tabel 2). Tingginya P-tersedia pada lahan ini disebabkan penggunaan 
pupuk SP-36 secara terus menerus dan berlebihan sehingga sebagian pupuk P lebih banyak tertinggal di lahan. Pemberian pupuk secara berlebihan ini juga sesuai hasil wawancara dengan kelompok tani yang menerangkan bahwa penggunaan pupuk SP36 masih sering digunakan disetiap masa tanam, pada lahan sawah berproduksi tinggi pemberian pupuk SP36 sekali dalam masa penanaman padi dengan dosis pupuk SP36 yang diberikan yaitu $250 \mathrm{~kg}$ /ha, sedangkan pada lahan sawah berproduksi rendah pemberian pupuk SP36 dan NPK sampai dua kali dalam sekali masa penanaman padi, dengan dosis SP36 $60 \mathrm{~kg} / \mathrm{ha}$ dan NPK 60 $\mathrm{kg} / \mathrm{ha}$. Hal ini sesuai dengan penelitian Junita et al., (2013), bahwa pemberian pupuk buatan yang yang digunakan petani yaitu SP-36 dapat meningkatkan ketersedian unsur hara P di dalam tanah.

Ketersedian $\mathrm{P}$ yang tinggi juga dapat dipengaruhi oleh sistem pengairan atau penggenangan yang dilakukan oleh petani setempat, Prasetyo dalam Triharto (2013) menjelaskan bahwa penggenangan lahan akan menambah jumlah hara $\mathrm{P}$ tersedia karena adanya proses reduksi $\mathrm{Fe}^{3+}$ menjadi $\mathrm{Fe}^{2+}$ saat penggenangan berlangsung, sehingga ikatan $\mathrm{Fe}-$ $\mathrm{P}$ menjadi terlepas. Ketersediaan unsur hara Fosfor $(\mathrm{P})$ maksimun sering dijumpai pada $\mathrm{pH}$ 5,5-7. Pada $\mathrm{pH}$ tanah rendah dari 5,5 atau lebih tinggi dari 7 ketersediaan $\mathrm{P}$ akan menurun. Winarso (2005) menjelaskan bahwa $\mathrm{pH}$ tanah sangat erat hubungannya dengan ketersediaan unsur hara fosfor $(\mathrm{P})$ di dalam tanah.

Nilai $\mathrm{pH}$ pada lahan sawah berproduksi Tinggi rata-rata 7,35, sedangkan nilai $\mathrm{pH}$ pada lahan sawah berproduksi rendah rata-rata 7,24, keduanya termasuk dalam kriteria netral (Tabel 2). Hal ini disebabkan karena pengambilan sampel tanah dilakukan pada saat dimana kondisi tanah dalam keadaan tergenang. Tanah sawah dalam keadaan tergenang dapat meningkatkan $\mathrm{pH}$ tanah. Naiknya $\mathrm{pH}$ tanah yang digenangi karena reduksi $\mathrm{Fe}^{3+}$ menjadi $\mathrm{Fe}^{2+}$, akibat terjadi pembebasan $\mathrm{OH}^{-}$dan konsumsi $\mathrm{H}^{+}$. Hal ini sesuai dengan penyataan yang dinyatakan oleh Hardjowigeno dan Rayes (2005) yaitu pengenangan menyebabkan pH semua tanah mendekati netral kecuali pada tanah dengan kadar $\mathrm{Fe}$ aktif $\left(\mathrm{Fe}^{2+}\right)$ yang rendah atau tanah gambut. Perubahan $\mathrm{pH}$ akibat pengenangan dapat disebabkan oleh beberapa faktor, yang perubahan $\mathrm{Fe}^{3+}$ menjadi $\mathrm{Fe}^{2+}$ sulfat menjadi sulfida dan $\mathrm{CO}_{2}$ menjadi $\mathrm{CH}_{4}$. Nilai $\mathrm{pH}$ netral dapat mempengaruhi tingkat penyerapan unsur hara oleh akar tanaman, dikarenakan pada $\mathrm{pH}$ netral unsur hara mudah larut dalam larutan tanah (Hardjowigeno, 2007).

Menurut Sudaryono (2009) pada $\mathrm{pH}$ yang rendah yaitu kurang dari 5,5 ion fosfat akan diikat oleh unsur Fe dan Al sebagai senyawa yang tidak dapat larut dalam air. Kadar Fe pada lahan sawah berproduksi tinggi rata-rata $18,30 \mathrm{ppm}$, sedangkan kadar Fe pada lahan sawah berproduksi rendah rata-rata 31,76 ppm, keduanya termasuk dalam kriteria sedang. (Tabel 2).

Kadar Fe pada lokasi penelitian bervariasi dari rendah sampai sedang, hal ini dikarenakan kadar Fe pada kriteria sedang akibat banyaknya pengenangan dibandingkan pengeringan pada lahan sawah tersebut, Sedangkan Fe pada kriteria rendah dikarenakan pengenangan dan pengeringan dengan selang waktu yang lama. Hal ini sesuai dengan penelitian Prasetyo (2006) bahwa sawah yang digenangi secara terus menerus dapat meningkatnya kadar $\mathrm{Fe}^{2+}$ dalam larutan tanah, karena pada saat itu terjadi perubahan proses oksidasi menjadi proses reduksi, dimana $\mathrm{Fe}^{3+}$ dalam bentuk $\mathrm{Fe}(\mathrm{OH})_{3}$ yang tidak larut direduksi menjadi $\mathrm{Fe}^{2+}$ dalam bentuk $\mathrm{Fe}(\mathrm{OH})_{2}$ menjadi larut sehingga jumlahnya tersedia dalam larutan tanah, sedangkan kadar $\mathrm{Fe}^{2+}$ dalam tanah akibat pengenangan yang diselingi pengeringan selama satu minggu, dua minggu, tiga minggu dapat berkurang. Penurunan kadar $\mathrm{Fe}^{2+}$ ini dikarenakan adanya $\mathrm{Fe}^{2+}$ yang tercuci akibat pengeringan dan adanya proses oksidasi $\mathrm{Fe}^{2+}$ menjadi $\mathrm{Fe}^{3+}$ akibat kondisi tanah lebih oksidatif. Kadar $\mathrm{Fe}^{2+}$ jika dilakukan pengenangan 
dan pengeringan dengan selang waktu yang semakin lama akan diperoleh kadar $\mathrm{Fe}^{2+}$ yang semakin kecil.

Menurut Sudaryono (2009) pada pH tinggi yaitu diatas 7,0 ion fosfat akan bereaksi dengan unsur $\mathrm{Ca}$ dan $\mathrm{Mg}$ sehingga membentuk senyawa yang tidak dapat larut dalam air dan menjadi tidak tersedia bagi tanaman. Kadar Ca pada lahan sawah berproduksi tinggi rata-rata $31,57 \mathrm{mg} / 100 \mathrm{~g}$, sedangkan pada lahan sawah berproduksi rendah rata-rata 36,48 mg/100 g, keduanya termasuk kriteria sangat tinggi (Tabel 2). Tingginya Ca dikarenakan akibat adanya pengenangan sehingga kation-kation tidak mudah tercuci oleh air hujan dan air perkolasi. Hal ini sesuai dengan pernyataan Rahayu et al., (2014) tingginya kation dalam tanah yang disawahkan disebabkan rendanya pencucian yang terjadi akibat adanya lapisan tapak bajak yang dapat menghambat pergerakan air kebawah.

Ketersediaan $\mathrm{P}$ juga dipengaruhi oleh kandungan bahan organik dalam tanah yang berperan dalam mempengaruhi jerapan hara $\mathrm{P}$ di dalam tanah. Hal ini sesuai dengan pendapat Lumbaranja et al., (2003), yang menyatakan ketersedian bahan organik dapat mempengaruhi jerapan $\mathrm{P}$ di dalam tanah. Tanah yang memiliki kadar bahan organik tinggi akan memiliki jerapan $\mathrm{P}$ yang rendah begitupun sebaliknya.

Kadar C-organik pada lahan sawah berproduksi tinggi rata-rata 2,77 \%, sedangkan pada lahan sawah berproduksi rendah kadar C-organik rata-rata 2,93\%, keduanya termasuk kriteria sedang (Tabel 2). Hal ini diduga karena adanya pemberian bahan organik secara teratur dan disebabkan oleh jerami, sisa-sisa akar tanaman padi pada tanah yang disawahkan yang mengalami proses dekomposisi yang lebih lambat akibat adanya pengenangan, sehingga dapat mengawetkan bahan organik. Menurut pendapat Arabia (2009), pada tanah sawah toposekuen berbahan induk vulkanik di daerah Bogor-Jakarta mengemukakan bahwa sawah yang sering digenangi atau dalam suasana reduktif cenderung dapat mengawetkan bahan organik.

$\mathrm{pH}$ yang netral dan keberadaan bahan organik dapat menaikkan nilai KTK tanah sawah. Nilai KTK pada lahan sawah berproduksi tinggi rata-rata 68,64 mg/100 g, sedangkan pada lahan sawah berproduksi rendah rata-rata $65,75 \mathrm{mg} / 100 \mathrm{~g}$, keduanya termasuk kriteria sangat tinggi (Tabel 2). Nilai KTK tanah dapat dipengaruhi oleh bahan organik tanah, jika bahan organik dalam tanah tinggi maka KTK nya juga tinggi dan sebaliknya dan nilai KTK tanah juga dipengaruhi oleh mineral tanah Hardjowigeno (2003).

\section{P-total}

Kadar P-total pada lahan sawah berproduksi tinggi rata-rata 0,56 mg/100 g (5600 ppm), sedangkan pada lahan sawah berproduksi rendah rata-rata 0,89 mg/100 g (8900 ppm), keduanya termasuk kriteria sangat rendah (Tabel 2). Rendahnya P total pada lahan sawah tersebut diduga karena kandungan unsur $\mathrm{P}$ dalam bahan organik sangat rendah dan tanah tersebut terbentuk dari mineral-mineral yang miskin unsur hara P. Hal ini sesuai dengan pernyataan Munawar (2013) unsur P dalam tanah berasal dari hasil dekomposisi bahan organik dan desintegrasi mineral yang mengandung P seperti mineral apatit.. Kelarutan unsur $\mathrm{P}$ anorganik dan unsur $\mathrm{P}$ organik dalam tanah pada umumnya sangat rendah, sehingga sebagian kecil unsur $\mathrm{P}$ tanah yang berada dalam larutan tanah (P total) Sulakhudin et al., (2016).

\section{Evaluasi Kesuburan Lahan Sawah}

Hasil survai dan wawancara dengan petani pada lahan sawah berproduksi rendah (Desa Semeureng) yaitu, rendahnya produksi padi setiap tahunnya yang dihadapi petani dalam 
usahataninya di Desa Semeureng adalah (1) akibat pemberian pupuk tidak tepat waktu (2) serangan penyakit dan hama seperti: hama wereng,walang sangit, ulat, keong dan tikus dan (3) irigasi tidak mencukupi sebagian petakan sawah. Ketidakcukupan air di lahan sawah tersebut dipengaruhi juga oleh lokasi sawah yang berada di hilir yang mengakibatkan air irigasi tidak sampai dilokasi tersebut, sehingga sebagian petakan sawah di lokasi tersebut mengalami kekeringan.

Menurut Lafitte (2003) sawah dalam keadaan kering dapat menghambat tanaman padi terutama pada masa pembungaan. Galur padi yang berbunga dalam waktu tidak lama setelah pengairan dilakukan, akan lebih sedikit terpengaruh cekaman kekeringan dari pada galur padi yang berbunga lebih lambat. Fischer dan Fukai (2003) menyatakan pembungaan tanaman padi sering tertunda selama 2-3 minggu pada kondisi kekeringan. Pada saat curah hujan tinggi pada lokasi tersebut airnya melebihi dan saat curah hujan rendah air untuk pengenangan sawah tidak mencukupi sehingga petani di tempat tersebut menggunakan sumur bor untuk mengatasi ketidakcukupan air untuk pengairan sawah. Sedangkan pada lahan sawah berproduksi tinggi (Desa Leuthu lamweu) pengaturan irigasi dapat merata keseluruh petakan sawah karena lokasi sawah yang berada di pertengahan hulu dan hilir irigasi. Kendala yang yang dihadapi petani dalam usahataninya adalah serangan hama gosong pasu, tikus dan keong, akan tetapi tidak menghambat terhadap produksi padi.

\section{KESIMPULAN DAN SARAN}

Rata-rata P-tersedia pada lahan sawah berproduksi tinggi 21,83 ppm dan pada lahan sawah berproduksi rendah 24,43 ppm, keduanya termasuk dalam kriteria sangat tinggi, sedangkan rata-rata P-total pada lahan sawah berproduksi tinggi $0,56 \mathrm{mg} / 100 \mathrm{~g}$ dan pada lahan sawah berproduksi rendah $0,89 \mathrm{mg} / 100 \mathrm{~g}$, keduanya termasuk kriteria sangat rendah. Perbedaan produksi padi di Desa Luthu Lamweu dan seumereng disebabkan oleh perbedaan pengelolaan dan pengaturan irigasi yang tidak teratur. Adapun upaya yang dapat dilakukan yaitu pemantauan kesuburan tanah secara berkelanjutan karena siklus unsur hara tanah dapat berubah dalam waktu tertentu dan perlu dilakukan pengaturan irigasi secara teratur sehingga dapat mencukupi air keseluruh petakan sawah dan dapat meningkatkan produksi padi.

\section{DAFTAR PUSTAKA}

Arabia, T. 2009. Karakteristik Tanah Sawah pada Toposekuen Berbahan Induk Volkanik di Daerah Bogor-Jakarta. Disertasi. Repository.

Fischer, K.S. and S. Fukai. 2003. How Rice Responds to Drought. In K.S Fischer, R. Lafitte, S. Fukai, G. Atlin and b Hardy. Breeding Rice for Drought-Prone Environments. International Rice Research Institute. Los Banos. p. 32-36

Hardjowigeno, S. 2007. Ilmu Tanah. Penerbit Pusaka Utama. Jakarta.

Hardjowigeno, S dan M.L. Rayes. 2005. Tanah Sawah. Karakteristik, Kondisi dan Permasalahan Tanah di Indonesia. Bayumedia Publishing Anggota IKAPI Jatim. Malang.

Hardjowigeno, S. 2003. Ilmu Tanah. Akademika Pressindo. Jakarta. 
Junita, Jamilah, dan Sarifuddin. 2013. Kajian Sifat Kimia Tanah Sawah dengan Pola Pertanman Padi Semangka di Desa Air Hitam Kecamatan Lima Puluh Kabupaten Batubara. Jurnal Online Agroekoteknologi. 1: (4).

Liferdi, L. 2010. Efek Pemberian Fosfor Terhadap Pertumbuhan dan Status Hara Pada Bibit Manggis. Jurnal Hortikultura. 20: 18 - 26. (2).

Lumbanraja, J., R. Sitorus, S. Yusnaini, Sarno, A. Watanabe, M. Kimura, and M. Nonaka. 2003. Phosphorus Adsorption and Inorganic-Organic Phosphorus fraction of Haloysitic Soil in Different Land Use Changes in a Hilly Area of Sumberjaya, West Lampung of Sumatera. In M. Nonaka (editor): Final Report of Soil Fertility and Rehabilitation of Cultivated Tropica Rain Forest in South East Asia : 41-54.

Munawar, A. 2013. Kesuburan Tanah dan Nutrisi Tanaman. IPB Press, Bogor.

Prasetyo, T., B. Ruhaiman. S.A. Wardhana. 2006. Pengaruh Pengelolaan Air Terhadap Konsentrasi Besi (Fe) pada Sawah Bukaan Baru. Jurnal Solum. 3: 8-18. (3).

Rahayu, A., S.R. Utami, dan M.L. Rayes. 2014. Karakteristik dan Klasifikasi Tanah Lahan Kering dan Lahan yang disawahkan di Kecamatan Perak Kabupaten Jombang. Jurnal Tanah Sumberdaya Lahan. 1: 79-87. (2).

Sudaryono. 2009. Tingkat Kesuburan Tanah Ultisol pada Lahan Pertambangan Batubara Sangatta, Kalimantan Timur. Jurnal teknik Lingkungan. 10: 337-346. (3).

Sulakhudin. D. Suswati dan S. Gafur. 2016. Kajian Status Kesuburan Tanah pada Lahan Sawah di Kecamatan Sungai Kunyit Kabupaten Menpawah. Jurnal Pedon Tropika Edisi 1. 3: 106-114.

Triharto S. 2013. Survei dan pemetaan hara N,P,K dan pH pada lahan Sawah Tadah Hujan di Desa Durian Kecamatan Pantai Labu. Skripsi. Universitas Sumatera Utara. Medan.

Winarso, S. 2005. Kesuburan Tanah. Gava media. Yogyakarta. 